\title{
Evaluation of the Accuracy of the Saskatchewan Health Pharmaceutical Information Program for Determining a Patient's Medication Use Immediately before Admission
}

\author{
Joanie Tulloch and Barb Evans
}

\begin{abstract}
Background: The Pharmaceutical Information Program (PIP) administered by Saskatchewan Health provides records for individual patients of prescription medications and some over-the-counter products obtained with a prescription and processed through the provincial drug plan. Use of the PIP to assist in obtaining a medication history on admission to hospital has been advocated; however, the accuracy of the database has never been investigated.
\end{abstract}

Objective: To quantify the extent of agreement between a patient's PIP profile and a Best Possible Medication History (BPMH) for determining the patient's prescription medication use on admission to hospital.

Methods: General medicine patients admitted to 1 of the 2 clinical teaching units at the authors' hospital were reviewed for eligibility. A copy of the patient's PIP profile was printed, reviewed, and used in the course of obtaining a BPMH from consenting patients. The number and type of medication discrepancies and the time required to complete medication histories were documented.

Results: Fifty patients were interviewed. For 39 patients (78\%), one or more prescription discrepancies were identified between the PIP profile and the BPMH (mean 2.0, standard deviation 2.3, range 0-6). The top 3 prescription discrepancies were medication incorrectly appeared inactive in the PIP profile (49/101 discrepancies [49\%]), dosing discrepancy (28/101 [28\%]), and medication did not appear in the PIP profile (13/101 [13\%]). The most common reasons for prescription discrepancies were recent change in dosage or medication (18 [18\%]), compliance packaging (13 [13\%]), noncompliance (12 [12\%]), and entry error at the dispensing pharmacy (12 [12\%]). Mean total time to prepare for and conduct interviews was $22.5 \mathrm{~min}$ (range 10-54 min).

Conclusion: A patient's PIP profile may contain incomplete, inaccurate, or misleading information. Although the profile may be used to prompt the health care provider during a BPMH interview, it should never be used as a substitute for communicating directly with the patient.

\section{RÉSUMÉ}

Contexte : Le Programme d'information pharmaceutique (PIP) administré par le ministère de la Santé de la Saskatchewan fournit des registres individuels sur les médicaments d'ordonnance et sur certains médicaments en vente libre obtenus sur ordonnance et traités par le régime provincial d'assurance-médicaments. On a préconisé l'utilisation du PIP pour faciliter l'obtention de l'historique des médicaments lors de l'admission des patients à l'hôpital, mais on n'en a jamais évalué l'exactitude des données.

Objectif : Évaluer quantitativement la concordance entre le registre du PIP et le meilleur schéma thérapeutique possible (MSTP) afin de déterminer l'utilisation des médicaments d'ordonnance à l'admission d'un patient à l'hôpital.

Méthodes : Les patients de médecine générale admis à l'une des deux unités d'enseignement clinique de l'hôpital des auteurs ont été considérés quant à leur admissibilité à l'étude. Une copie du registre du PIP a été imprimée, examinée et utilisée pour obtenir le MSTP des patients consentants. Le nombre et le type de différences relativement aux médicaments et le temps nécessaire pour obtenir l'historique des médicaments ont été consignés.

Résultats : Cinquante patients ont été interviewés. On a relevé chez $39(78 \%)$ d'entre eux au moins une différence relative aux médicaments d'ordonnance entre les données issues du registre du PIP et celles issues du MSTP (moyenne de 2,0, écart-type de 2,3 et intervalle de 0 à 6). Des 101 différences détectées, les trois principales avaient trait à des médicaments dont le statut était inactif dans le registre du PIP (49/101 [49\%]), à des posologies dissemblables (28/101 [28 \%]) et à des médicaments qui n’apparaissaient pas dans le registre du PIP $(13 / 101$ [13 \%]). Les principales raisons expliquant les différences dans les médicaments d'ordonnance étaient des changements récents dans la posologie (18 [18\%]), la délivrance des médicaments dans un pilulier (13 [13\%]), la non-observance thérapeutique (12 [12\%]) et des erreurs de saisie à la pharmacie qui a exécuté l'ordonnance (12 [12\%]). Le temps total moyen pour préparer et passer l'entrevue était de $22,5 \mathrm{~min}$ (fourchette de 10 à $54 \mathrm{~min}$ ). 
Key words: prescription drug database, accuracy, effectiveness, medication history

Can J Hosp Pharm 2009;62(1):21-27
Conclusion : Les registres des patients du PIP peuvent contenir de l'information incomplète, inexacte ou trompeuse. Bien qu'ils puissent servir de guide au fournisseur de soins de santé lors de l'entrevue pour établir le MSTP, ils ne doivent en aucun cas remplacer la communication directe avec le patient.

Mots clés : base de données sur les médicaments d'ordonnance, exactitude, efficacité, historique des médicaments

[Traduction par l'éditeur]

\section{INTRODUCTION}

$M$ edication errors occur with disturbing frequency and are a leading cause of morbidity and mortality in patients who have been admitted to hospital. ${ }^{1,2}$ More than half of all hospital medication errors occur at the interfaces of care, with over one-quarter of all hospital prescribing errors attributed to incomplete medication histories obtained at the time of admission. $^{3}$ Cornish and others ${ }^{2}$ found that $53.6 \%$ of general medicine patients had at least one unintended medication discrepancy at the time of hospital admission, the most common type being the omission of a regularly scheduled medication. Over a third of these discrepancies had the potential to cause moderate to severe harm. ${ }^{2}$ These results are comparable to those obtained in previous studies. For example, Beers and others ${ }^{4}$ interviewed 122 elderly inpatients and found that $60 \%$ of the study population had one or more discrepancies on admission. Lau and others 5 found that $26 \%$ of the prescription medications that patients were taking before admission were not recorded in their hospital records.

Obtaining an accurate medication history at the time of hospital admission is critical to ensuring safe and effective patient care. 2,6 Incomplete or inaccurate medication histories may lead to unintended discontinuation of a medication, unnecessary drug therapy, and/or failure to detect drug-related problems. $^{5}$

Obtaining a complete and accurate medication history can be difficult, given the many factors that affect the accuracy and completeness of the information, such as time available to conduct the interview, severity of the patient's illness, patient's cognitive status, patient's familiarity with his/her medication regimen, availability of medication vials and/or a medication list, and presence of language barriers., ${ }^{2,7}$ The experience and training of the interviewer can be another factor. Without a formalized process for gathering the information, the reliability and validity of the history can be questionable. ${ }^{8}$

Options for improving the accuracy and reliability of medication histories obtained at the time of admission have been investigated. These options include providing further training for admitting physicians and other health care personnel and integrating computer systems to allow the transfer of prescription drug information between community and hospital pharmacies. $^{2}$

The Pharmaceutical Information Program (PIP) was developed in Saskatchewan and introduced in fall 2005. It is a comprehensive database of dispensing records provided by the Saskatchewan Drug Plan. It enables approved health care providers to access prescription medication information for all residents of Saskatchewan who hold a current Saskatchewan health card, regardless of their age. The profile reflects historical information on medications dispensed, to a maximum of 1 year. The following medications are not listed in a patient's PIP profile: medications prescribed, dispensed, and administered in hospital; medications covered by the Saskatchewan Cancer Agency or the Tuberculosis Control Program; investigational or study medications; medication samples; over-the-counter medications purchased without a prescription; and herbal products. In addition, out-of-province pharmacies located on the Saskatchewan border are not required to send their information to the Saskatchewan Drug Plan.

The Saskatoon Health Region plans to use the provincial drug database to obtain PIP profiles for patients admitted to the hospital; it also plans to download PIP information to a medication reconciliation form that will be completed at the time of admission. However, the accuracy of the PIP profile in relation to patients' actual medication use before admission has never been investigated. We undertook a study to quantify the extent of agreement between the PIP profile and the Best Possible Medication History (BPMH; obtained by a pharmacist) for individual patients in determining patients' medication use at the time of admission to hospital. The study objectives were to determine the accuracy and effectiveness of the PIP for determining a patient's use of prescription medications immediately before admission, to identify any discrepancies between the patient's PIP profile and his or her BPMH as obtained by a pharmacist, to categorize any medication 
discrepancies identified between the patient's PIP profile and the BPMH, and to quantify the workload required for the pharmacist to obtain the BPMH.

\section{METHODS}

This prospective, nonrandomized study was approved by the University of Saskatchewan Behavioural Research Ethics Board.

Residents of Saskatchewan with a Saskatchewan health card who were at least 18 years of age and who were admitted between December 1, 2006, and March 31, 2007, as general medicine patients to either of 2 clinical teaching units (within the same ward) in the Saskatoon Health Region were eligible to participate in the study. Patients were excluded if they were unable to speak or understand English, had an obvious cognitive impairment, were unconscious or critically ill, or had been transferred from a hospital or long-term care facility in which they or their primary caregiver was not in charge of administering their medications.

To identify potential participants, the pharmacist printed a computer-generated list of new admissions each day. For each patient on the list, the medical chart was reviewed to screen for eligibility. If eligible, patient consent was requested; for patients who granted consent, the pharmacist then accessed the PIP profile to generate a list of the medications that had been dispensed in the previous 4 months. The following information appeared on the printed PIP profile: drug name, strength of the medication dispensed, dispensing date, quantity dispensed, duration of supply (number of days), name and phone number of the pharmacy that dispensed the medication, and name of the prescribing physician. A medication was considered inactive if the most recently dispensed supply counted down to zero before the date of hospital admission. The total daily dose for each medication was determined by dividing the total quantity of medication dispensed by the number of days' supply. These rules applied for both as-needed and regularly scheduled medications, as there is no way to identify as-needed medications from the PIP profile. A 4-month PIP profile was chosen to ensure that medications dispensed as a 100-day supply would appear on the profile. After reviewing the patient's PIP profile, the pharmacist prepared a BPMH with the patient and/or caregiver. For each medication that the patient stated he or she was taking, the pharmacist documented the dose, frequency, indication for use, and duration of therapy. Information on compliance and side effects was also obtained. When necessary, the pharmacist contacted the patient's community pharmacies, physicians, or other hospitals for clarification of the patient's home medications. If any discrepancies were identified in which a medication that the patient reported taking was not listed on the patient's 4-month PIP profile, the pharmacist then reviewed and printed a 12-month PIP profile. The 12-month profile was assumed to catch multiple prior fills of a medication (i.e., stockpiling), any medications with which the patient might not be compliant, and as-needed medications not dispensed in the previous 4 months but still being taken by the patient. The 12-month PIP profile was printed and reviewed only when needed, as it is the 4-month profile that the Saskatoon Health Region is considering downloading to a medication reconciliation form, and we therefore wanted to determine its accuracy for determining patients' medication use before admission. Information obtained from the BPMH was documented on the standardized data collection form. Any discrepancies identified between a patient's PIP profile and the BPMH were described and coded. Discrepancies with the potential to affect the patient's care and safety were resolved by the investigator (J.T.). The time required to access and print the patient's PIP profile, review the medical chart, and obtain the BPMH was documented.

Statistical analysis was performed using SPSS version 15. Statistical significance was defined as $p<0.05$, as determined by a paired $t$ test.

\section{RESULTS}

During the study, 91 medical charts were reviewed. Thirty-nine (43\%) patients were deemed ineligible on the basis of predefined inclusion and exclusion criteria. The other 52 patients were approached by the primary investigator (J.T.), and $50(96 \%)$ of these provided written informed consent to participate in the study.

The mean age of the study population was 64.6 years (standard deviation [SD] 18.1, range 20-95), and 27 (54\%) were female. Seventeen (34\%) of the 50 patients reported an allergy to at least one medication. The most common reasons for admission were gastrointestinal (11 patients [22\%]), infectious disease (9 patients [18\%]), cardiovascular (7 [14\%]), and respiratory $(7[14 \%])$. Seventeen patients (34\%) had been admitted to hospital in the preceding year.

The primary investigator (J.T.) completed a BPMH with each of the 50 patients. The mean interview time was $12.4 \mathrm{~min}$ (SD 6.0, range 3-35). In addition, $4.8 \mathrm{~min}$ (SD 1.4, range 2-10) was spent reviewing the patient's medical chart, $1.1 \mathrm{~min}$ (SD 0.3, range 1-2) accessing the patient's PIP profile, and 4.2 min (SD 2.2, range 0-11) reviewing the patient's PIP profile before obtaining the BPMH. The mean total time spent per patient was $22.5 \mathrm{~min}$ (range 10-54). Nine patients (18\%) had medication vials, a medication list, and/or a compliance pack available for inspection. Medications were clarified with the community pharmacy (34 patients [68\%]), family physician (4 [8\%]), and/or caregiver (7 [14\%]) when necessary.

The PIP is not designed to capture nonprescription or herbal medications that a patient may be taking. As a result, the 
remainder of the results section focuses on discrepancies related to prescription medications only. During the interviews, patients reported taking a total of 378 medications (mean 7.6 per patient, SD 4.8, range 1-19); 75\% (282) of these were prescription medications. The mean number of prescription medications per patient, based on the interview, was 5.6 (SD 4.2, range $0-16$ ), and the mean number of active prescription medications per patient from the PIP profile was 4.5 (SD 4.3, range $0-18)(p<0.001)$ (Table 1).

A total of 101 prescription medication discrepancies were identified between the PIP profile and the BPMH. Eleven $(22 \%)$ of the 50 patients had complete agreement between their PIP profile and the prescription medications they reported taking before admission, but 39 patients (78\%) had one or more discrepancies involving a prescription medication. A mean of 2.0 (SD 2.3, range 0-6) prescription discrepancies were identified per patient (Table 2 ).
The top reason for prescription discrepancies was a patient's medication incorrectly appearing as inactive in the PIP profile (Table 3). The discrepant medication was listed on the 4-month PIP history in $88(87 \%)$ of the 101 cases, but incorrectly appeared as inactive in 49 (49\%) cases. Eight (16\%) of these 49 discrepancies were due to dosage changes initiated by the patient $(n=5)$ or the physician $(n=3)$, and $13(27 \%)$ were the result of compliance packaging.

The second most common form of discrepancy was a difference between the patient's reported total daily dose and that recorded in the PIP profile (28/101 [28\%]). Warfarin, furosemide, and prednisone were the 3 prescription medications most commonly involved in this type of dosing discrepancy.

The third most common reason for prescription discrepancies was the absence of the patient's medication from the PIP profile (13/101 [13\%]). Six (46\%) of these 13 discrepancies

Table 1. Comparison of Number of Medications Obtained by Different Methods for 50 Patients

\begin{tabular}{lccc} 
& \multicolumn{2}{c}{ Total No. of Medications (Mean/Patient) } & \\
\cline { 2 - 3 } $\begin{array}{l}\text { Category of } \\
\text { Medication }\end{array}$ & By Interview & PIP Data & $\begin{array}{c}\text { Mean Difference } \\
\text { per Patient }\end{array}$ \\
\hline All & $378(7.6)$ & $235(4.7)$ & $2.9^{*}$ \\
Prescription only & $282(5.6)$ & $225(4.5)$ & $1.1^{*}$ \\
\hline PIP $=$ Pharmaceutical Information Program, SD = standard deviation. \\
${ }^{*} p<0.001$.
\end{tabular}

\section{Table 2. Discrepancies in Prescription Medications between 4-Month} PIP Profile and BPMH

\begin{tabular}{lccc} 
Type of Drug & No. (\%) of Discrepancies & Mean per Patient \pm SD & Range \\
\hline Regular drugs & $85(84)$ & $1.7 \pm 1.7$ & $0-6$ \\
As-needed drugs & $16(16)$ & $0.3 \pm 0.6$ & $0-2$ \\
Total & 101 & $2.0 \pm 2.3$ & $0-6$ \\
\hline
\end{tabular}

$\mathrm{BMPH}=$ Best Possible Medication History, PIP = Pharmaceutical Information Program, $\mathrm{SD}=$ standard deviation.

Table 3. Classification of Prescription Medication Discrepancies between 4-Month PIP Profile and BPMH

\begin{tabular}{|c|c|c|c|}
\hline \multirow[b]{2}{*}{ Type of discrepancy } & \multicolumn{3}{|c|}{ No. $(\%)$ of Discrepancies $(n=101) *$} \\
\hline & $\begin{array}{l}\text { Scheduled } \\
\text { Medications }\end{array}$ & $\begin{array}{c}\text { As-Needed } \\
\text { and As-Directed } \\
\text { Medications }\end{array}$ & Total \\
\hline Incorrectly appeared inactive & $38(38)$ & $11(11)$ & 49 (49) \\
\hline Incorrectly appeared active & $8(8)$ & $1(1)$ & $9(9)$ \\
\hline $\begin{array}{l}\text { Dose from BPMH > dose suggested } \\
\text { on PIP profile }\end{array}$ & $13(13)$ & 0 & $13(13)$ \\
\hline $\begin{array}{l}\text { Dose from BPMH }<\text { dose suggested } \\
\text { on PIP profile }\end{array}$ & $15(15)$ & 0 & $15(15)$ \\
\hline Drug not listed on PIP profile & $9(9)$ & $4(4)$ & $13(13)$ \\
\hline Drug strength not listed on PIP profile & $1(1)$ & 0 & $1(1)$ \\
\hline Drug name not listed on PIP profile & $1(1)$ & 0 & $1(1)$ \\
\hline
\end{tabular}

$\mathrm{BMPH}=$ Best Possible Medication History, PIP = Pharmaceutical Information Program.

${ }^{\star}$ All percentages are based on the total number of discrepancies. 
were due to the use of medication samples. Medications missing from the PIP profile occurred most frequently with inhaled respiratory agents $(6 / 13$ [46\%]). Medication samples provided by the physician (4/6 [67\%]) and supplies from a recent hospital stay (2/6 [33\%]) accounted for these discrepancies. Other prescription medications that patients reported taking but that were absent from the PIP profile included prescription medications dispensed by the Saskatchewan Cancer Agency and old medications that had been restarted by the patient.

The most common reasons for the 101 prescription medication discrepancies were recent dosage or medication change (18 [18\%]), compliance packaging (13 [13\%]), noncompliance $(12[12 \%])$, entry error at the dispensing pharmacy (12 [12\%]), recent discontinuation of a medication (8 [8\%]), and use of as-needed or as-directed medication (8 [8\%]). The most common categories of prescription medications involved in the discrepancies were cardiovascular (21 [21\%]), inhaled respiratory (16 [16\%]), endocrine (14 [14\%]), fluid and electrolyte (12 [12\%]), and psychiatric (7 [7\%]) agents.

The patient's 12-month PIP profile was helpful in clarifying the prescription discrepancy in $2(15 \%)$ of the 13 cases in which the 12-month profile was reviewed.

\section{DISCUSSION}

The purpose of this study was to determine the extent of agreement between the prescription medications listed on a patient's PIP profile and a BPMH obtained by a pharmacist. Of the 50 PIP profiles reviewed, $78 \%$ contained one or more identified discrepancies involving a prescription medication. In general, the PIP profile tended to underestimate the mean number of medications per patient (mean difference of 1.1 between numbers reported in the interview and the PIP profile; $p<0.001$ ). These results are similar to those obtained in a recent study of the accuracy of British Columbia's provincial drug database, PharmaNet, for medication profiles of patients with heart failure.' Over $70 \%$ of the PharmaNet profiles reviewed in that study contained inaccurate or misleading information about the patient's current medication consumption. The most common type of discrepancy involved medications that appeared in PharmaNet but were overdue for a refill (i.e., incorrectly appeared as inactive).

The most common prescription discrepancy identified in the study reported here was one or more of the patient's current prescription medications incorrectly appearing inactive in the PIP profile. Sole reliance on the PIP to determine the prescription medications that a patient was taking before admission might therefore result in unintentional omissions of medications. Numerous reasons for this discrepancy were identified, including recent changes to the patient's medication or dosing regimen, whether initiated by the patient or by the physician.
Often, the patient's actual daily dose was less than the total daily dose calculated from the PIP profile. As a result, the medication dispensed would last the patient longer than the number of days' supply suggested by the PIP profile. Therefore, a risk of prescribing too much medication exists if the PIP profile is used to calculate the dose on admission without confirming the information with the patient. Physicians must be encouraged to prescribe the dose and regimen they want the patient to follow, so that the prescription label and the PIP database are accurate. Attempts to save the patient money (by prescribing a larger dose of medication, with verbal instructions to take the medication differently from what is indicated on the prescription label) should be avoided.

Nearly one-third of the prescription medications that incorrectly appeared inactive on the PIP profiles had been dispensed in compliance packs. These packages are often prepared ahead of time to ensure that they are ready for the patient at the time of pick-up. Therefore, the fill date in the PIP profile often reflects the date when the prescription was processed by the pharmacy rather than the date the pack was started by the patient. As a result, the number of days' supply in the PIP profile counts down to zero and the medication appears inactive before the patient has completed the compliance pack. Pharmacists should be encouraged to enter into the PIP system the date on which use of the compliance pack will start, not the dispensing date.

PIP entry errors in the dispensing pharmacy constituted another reason why medications incorrectly appeared inactive on the PIP profile. When a prescription is dispensed from a community pharmacy, the pharmacist must enter the total quantity dispensed and the number of days' supply. In the current study, a total of 12 prescription discrepancies were identified in which an incorrect number of days was entered by the dispensing pharmacy. This resulted in a calculated daily dose significantly greater than the patient's actual daily dose and led to the medication incorrectly appearing inactive on the patient's PIP profile. For example, in one case, an Atrovent (ipratropium) inhaler was incorrectly dispensed as a one-day supply. Community pharmacists should be reminded of the importance of entering the correct number of days' supply when dispensing prescription medications. Calculating the dose from the patient's PIP profile is not a reliable substitute for completing a medication history with the patient.

For the majority of discrepancies involving as-needed or asdirected prescription medications, the medication incorrectly appeared as inactive on the patient's PIP profile. This problem is difficult to avoid, as the dispensing pharmacy must enter the number of days' supply for each medication, which is often based on a "best guess" for usage. Salbutamol inhalers, nitroglycerin spray, and insulin were the 3 most common asneeded or as-directed medications that patients reported using 
but that appeared inactive on the corresponding PIP profile.

For $28(28 \%)$ of the 101 discrepancies involving prescription medications, the patient's total daily dose differed from the daily dose recorded in the PIP profile. This problem is difficult to avoid for medications for which doses are adjusted on the basis of blood tests (e.g., warfarin) or signs and symptoms (e.g., furosemide) and drugs with tapering regimens (e.g., prednisone). The reliability of the PIP profile in these circumstances is questionable, and dosing information must be obtained from the patient.

Patients admitted noncompliance in $12(12 \%)$ of the 101 identified prescription discrepancies. Such noncompliance resulted in a dosing discrepancy that might or might not have resulted in the medication incorrectly appearing inactive on the patient's PIP profile. The most common reason for noncompliance was unauthorized self-adjustment of the medication regimen.

Thirteen (5\%) of the 282 current prescription medications did not appear on the patients' 4- or 12-month PIP profiles. These accounted for $13 \%$ of the identified discrepancies involving prescription medications. When using PIP information to obtain a medication history, it is essential to ask the patient if they take any medication provided by the Saskatchewan Cancer Agency or Tuberculosis Control Program or any sample, investigational, special access, or study medications. Methods to capture prescribing information from other databases, along with information about sample, investigational, and study medications, should be investigated to ensure that patients' PIP profiles more accurately represent all of their current prescription medications.

Saskatchewan's Drug Plan uses temporary alphanumeric codes for medications that are new on the market. Identification of these medications within the PIP profile is not possible unless the patient can provide the name and strength of the medication dispensed. Although this situation accounted for a minimal number of discrepancies, it is important that the Drug Plan avoid the use of temporary codes. Instead, new medications should be entered into the PIP as soon as they are approved for use. A task force of the Canadian Society of Hospital Pharmacists is now working with Saskatchewan Health to improve the PIP database.

There were several limitations to this study. First, the study population was a small sample of adult patients admitted to one ward at a single hospital. Even though these patients had a wide range of clinical issues, the results reported here may not be representative of the general population. Second, $34 \%$ of the patients interviewed reported having been admitted to hospital in the previous year. This might have affected the number of discrepancies identified, as the authors know from experience that hospital admissions affect the frequency and timing of prescription refills. Third, medication doses and directions for use are not provided in the PIP profile. Therefore, the investigators calculated the daily dose from the amount of medication dispensed and the number of days' supply entered by the community pharmacy. Unfortunately, only $18 \%$ of the patients interviewed had a medication list, medication vials, and/or compliance pack available for inspection. Because of the stress of a hospital stay, the patient and/or the patient's primary caregiver may not remember the complete medication regimen, ${ }^{5}$ which might have affected the discrepancies that were identified. It would be interesting to evaluate the clinical implications of the discrepancies, but this was beyond the scope of the current study. A considerable amount of time was required to prepare for and interview each patient (mean 22.5 minutes). Reallocation of existing pharmacy resources or assignment of extra resources would be required to interview each newly admitted patient. Finally, the PIP is designed to capture information about prescription medications. Therefore, discrepancies between the PIP and the BPMH with respect to over-the-counter and herbal medications were not analyzed or reported.

From this study, it is evident that we need to educate patients to assume greater responsibility for their health care, specifically their use of prescription medications. The importance of carrying an accurate and up-to-date list of all current medications at all times needs to be stressed. A multifaceted educational approach is recommended to achieve this behavioural change.

\section{CONCLUSIONS}

Most prescription medications that a patient reported taking (during a BPMH interview) appeared somewhere in his or her PIP profile. However, in many cases these medications incorrectly appeared inactive and the total daily dose suggested in the PIP profile often differed from the patient's actual daily dose. Thus, the PIP profile can be used to assist the health care provider in determining a patient's medication use on admission but should never be used as a substitute for interviewing the patient.

\section{References}

1. 100,000 lives campaign. Getting started kit: prevent adverse drug events (medication reconciliation) how-to guide [Internet]. Cambridge (MA): Institute for Healthcare Improvement; [no date; cited 2006 Aug 10]. Available from: http://www.ihi.org

2. Cornish PL, Knowles SR, Marchesano R, Tam V, Shadowitz S, Juurlink $\mathrm{DN}$, et al. Unintended medication discrepancies at the time of hospital admission. Arch Intern Med 2005;165(4):424-429.

3. Safer healthcare now. Getting started kit: medication reconciliation. Prevention of adverse drug events how-to guide [Internet]. Edmonton (AB): Canadian Patient Safety Institute; [2005 Nov 6; cited 2006 Aug 10]. Available from: http://www.saferhealthcarenow.ca

4. Beers $\mathrm{MH}$, Munekata M, Storrie M. The accuracy of medication histories in the hospital medical records of elderly persons. J Am Geriatr Soc 1990;38(11):1183-1187. 
5. Lau HS, Florax C, Porsius AJ, De Boer A. The completeness of medication histories in hospital medical records of patients admitted to general internal medicine wards. Br J Clin Pharmacol 2000;49(6):597-603.

6. Patient safety goals and required organizational practices [Internet]. Ottawa (ON): Canadian Council on Health Services Accreditation; [no date; cited 2006 Aug 13]. Available from: http://www.cchsa.ca

7. Tam VC, Knowles SR, Cornish PL, Fine N, Marchesano R, Etchells EE. Frequency, type and clinical importance of medication history errors at admission to hospital: a systematic review. CMAJ 2005;173(5):510-515.

8. Nester TM, Hale LS. Effectiveness of a pharmacist-acquired medication history in promoting patient safety. Am J Health Syst Pharm 2002;59(22):2221-2225.

9. Shalansky S, Jang L, Ignaszewski A, Clark C, Jung L, Marra C. Accuracy of a prescription claims database for medication reconciliation for outpatients with heart failure. Can J Hosp Pharm 2007;60(3):169-176.
Joanie Tulloch, BSP, ACPR, is with the College of Pharmacy, University of British Columbia, Vancouver, British Columbia.

Barb Evans, BSP, ACPR, MSc, FCSHP is with the Pharmacy of the Saskatoon Health Region, Saskatoon, Saskatchewan.

\section{Address correspondence to:}

Barb Evans

Pharmacy

University Hospital

103 Hospital Drive

Saskatoon SK

S7N OW8

e-mail: barb.evans@saskatoonhealthregion.ca 